
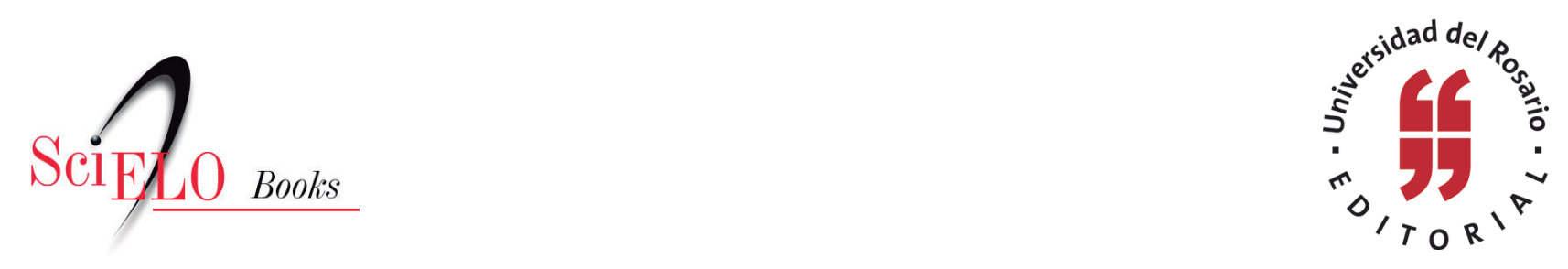

\title{
Cumplimiento de las condenas contra Colombia por desplazamiento forzado interno en el Sistema Interamericano
}

\author{
Johana Álvarez Rincón \\ Gabriel Alejandro Quintero Sánchez
}

\section{SciELO Books / SciELO Livros / SciELO Libros}

ÁLVAREZ RINCÓN, J., and QUINTERO SÁNCHEZ, G.A. Cumplimiento de las condenas contra Colombia por desplazamiento forzado interno en el Sistema Interamericano. In: TORRES VILLARREAL, M.L., and IREGUI PARRA, P.M., eds. El desplazamiento forzado en Colombia: 10 años de la sentencia T-025 de 2004: ponencias ganadoras del IV Concurso Nacional de Semilleros de Investigación [online]. Bogotá: Editorial Universidad del Rosario, 2015, pp. 1-38. Textos de Jurisprudencia collection, Semilleros series. ISBN: 978-958-738-559-5. https://doi.org/10.7476/9789587385595.0002.

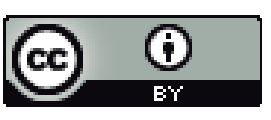

All the contents of this work, except where otherwise noted, is licensed under a Creative Commons Attribution 4.0 International license.

Todo o conteúdo deste trabalho, exceto quando houver ressalva, é publicado sob a licença Creative Commons Atribição $\underline{4.0}$.

Todo el contenido de esta obra, excepto donde se indique lo contrario, está bajo licencia de la licencia Creative Commons Reconocimento 4.0. 


\title{
Cumplimiento de las condenas contra Colombia por desplazamiento forzado interno en el Sistema Interamericano*
}

\author{
Johana Álvarez Rincón*" \\ Gabriel Alejandro Quintero Sánchez
}

* Ponencia desarrollada en el proyecto de investigación actualmente en ejecución "Cumplimiento de las sentencias de la Corte Interamericana de Derechos Humanos: Revisión del caso Colombiano en Perspectiva Comparada”, realizada conjuntamente por Johana Álvarez Rincón, auxiliar de Investigación, y Gabriel Alejandro Quintero Sánchez, miembros del Semillero de Investigación Observatorio en Justicia Constitucional y Derechos Humanos, y bajo la dirección de la líder de Investigación, la profesora Tania Giovanna Vivas Barrera, vinculados todos al Grupo de Investigaciones "Personas, Instituciones y Exigencias de Justicia”, adscrito al Centro de Investigaciones Sociojurídicas cisjuc de la Facultad de Derecho de la Universidad Católica de Colombia.

** Estudiante de noveno semestre de Derecho de la Universidad Católica de Colombia. Auxiliar de Investigación y miembro del Semillero de Investigación Observatorio en Justicia Constitucional y Derechos Humanos del Grupo de Investigaciones "Personas, Instituciones y Exigencias de Justicia”, adscrito al Centro de Investigaciones Sociojurídicas cisjuc de la Facultad de Derecho de la Universidad Católica de Colombia. Correo electrónico: ajalvarez09@ucatolica.edu.co

*** Estudiante de séptimo semestre de Derecho de la Universidad Católica de Colombia. Auxiliar de Investigación y miembro del Semillero de Investigación Observatorio en Justicia Constitucional y Derechos Humanos del Grupo de Investigaciones "Personas, Instituciones y Exigencias de Justicia", adscrito al Centro de Investigaciones Sociojurídicas cisjuc de la Facultad de Derecho de la Universidad Católica de Colombia. Correo electrónico: gaquintero89@ucatolica.edu.co 


\section{Resumen}

La población colombiana ha sido históricamente víctima de desplazamiento forzado interno, flagelo calificado hoy en día como delito de lesa humanidad. Los niveles de desplazamiento forzado ubican a Colombia encabezando los listados de las principales organizaciones en llevar a cabo el monitoreo de las estadísticas de desplazamiento forzado, de países con mayor índice de violaciones, de allí la importancia de vigilar el comportamiento del país. Por ello, partimos de considerar en un primer momento la información hoy disponible sobre la extensión geográfica de la violación, las causas y factores que influyen en los altos niveles y las circunstancias políticas, sociales y económicas que trae como consecuencia la presencia de este fenómeno. Concebimos además como asunto primordial tener en cuenta los niveles de cumplimiento de las sanciones impuestas por el Sistema Interamericano en las sentencias que han condenado la violación del derecho a la libre circulación consagrado en la Convención Americana de Derechos Humanos.

\section{Palabras clave}

Corte Interamericana de Derechos Humanos, desplazamiento forzado, cumplimiento, sentencias.

\section{Introducción}

El estudio del presente caso tiene dos focos de análisis de la situación colombiana. La primera parte de la investigación tiene como base estructural el establecimiento de lo que consideramos como desplazamiento interno, además se concentrará en la posición internacional que ha ganado el país dentro de las estadísticas mundiales y continentales sobre este fenómeno. La segunda parte de la investigación está encaminada a analizar todas las condenas contra el Estado colombiano emanadas de 
la Corte Interamericana de Derechos Humanos y los niveles de cumplimiento de las órdenes recogidas en las sentencias.

\section{Metodología}

El método investigativo empleado en la presente ponencia es un método mixto, entre una descripción de la realidad objeto de estudio, el análisis de cifras, la situación de desplazamiento forzado a nivel mundial respecto del caso colombiano, la comparación en relación a los índices sobre el desplazamiento en diferentes países también en conflicto y un análisis de caso desde la perspectiva del Sistema Interamericano de Derechos Humanos y los casos contenciosos contra Colombia en lo relacionado con víctimas de desplazamiento forzado y la responsabilidad del Estado frente a las consecuencias que esta puede generar. Así, se podrá entonces inferir cuál es el nivel de cumplimiento de las órdenes dictadas por la Corte Interamericana de Derechos Humanos y cuáles son las garantías para las personas víctimas de este fenómeno.

\section{Primera parte. Colombia en las estadísticas internacionales sobre desplazamiento forzado interno}

\section{¿Qué se entiende por desplazado?}

Según la Oficina para la Coordinación de Asuntos Humanitarios de las Naciones Unidas (en adelante, OCAH) por desplazado ha de entenderse: "de acuerdo con los principios rectores de desplazamiento interno, los desplazados internos" $[\text { DI, en adelante }]^{1}$ son

\footnotetext{
1 IDPs. Internal Displacement Person, traducido al español, IDP, Personas Desplazadas Internas.
} 
[...] personas o grupos de personas que han sido forzadas u obligadas a escapar o huir de su hogar o lugar habitual de residencia, en particular como resultado o para evitar los efectos de un conflicto armado, situaciones de violencia generalizada, violaciones de derechos humanos o de catástrofes naturales o hechos realizados por el hombre, y que no han cruzado una frontera estatal internacionalmente reconocida (Principios Rectores de los Desplazamientos Internos, Art. 2).

El conflicto armado colombiano ha representado en América Latina una violencia abismal, ello se demuestra en la cantidad de personas que a la actualidad son víctimas del conflicto armado interno y debido a circunstancias de hecho han tenido que desplazarse de lo que conocen como sus hogares.

\section{Panorama internacional}

El estudio y análisis internacional de estadísticas de desplazamiento interno ha sido realizado por diferentes organizaciones, La principal organización internacional que ha llevado el seguimiento de las cifras y estadísticas ${ }^{2}$ internacionales es el Observatorio de Desplazados Interno (IDMc, en adelante). ${ }^{3}$

2 El IDMc realiza una búsqueda y recopilación de información de distintas fuentes, tal como son los gobiernos nacionales, de las Naciones Unidas, de organizaciones nacionales e internacionales no gubernamentales (ONG), organizaciones de derechos humanos, los medios de comunicación. Además que esta organización lleva a cabo misiones sobre el terreno a un número de países cada año para corroborar información o para encontrar nuevas estadísticas que aún no se han encontrado.

3 El Observatorio de Desplazados Internos (IDMC) es líder mundial en el seguimiento y análisis de las causas, efectos y respuestas a la cuestión de los desplazados internos, hace parte del Consejo Noruego para los Refugiados (NRC), organización no gubernamental internacional, independiente, humanitaria, sin ánimo de lucro, establecida en 1964. 
El problema social pertinente al desplazamiento tiene una connotación a nivel mundial, debido a que se presenta en los diferentes continentes del mundo. El IDMc elabora su estudio en las siguientes locaciones geográficas: América, África Subsahariana, en el Sur y Sudeste de Asia, en Medio Oriente, África del Norte, la zona del Cáucaso en Europa ${ }^{4}$ y Asia Central.

El continente africano es el continente que alberga la mayor cantidad de desplazados alrededor del mundo con 10,4 millones de desplazados internos, comprendiendo casi un tercio del total mundial. En el África Subsahariana los países que presentan mayores índices de personas desplazadas según los últimos estudios del IDMC son República Democrática del Congo con 2’634.872, Sudán con 2`426700, Somalia con 1'100.000 y Sudán del Sur con 956.200 DI, los cuales son los casos más dramáticos. Los menos dramáticos son Eritrea con 10.000, Liberia con 23.000, Togo con 1.500 y Níger con 11.000 Di. Cabe resaltar que hay países en los cuales no se tienen estudios recientes y ello dificulta establecer cifras actualizadas de este fenómeno; otros se encuentra en la posición en la cual ha podido establecerse una cifra como tal, como se presenta en el caso de Nigeria y Zimbawe. En el África del Norte, Argelia tiene cifras indeterminadas y Argelia contempla una cifra aproximada de 59.000 Di. La mayoría de los países en el continente africano ostenta una cifra entre 20.000 y 500.000 DI (IDMC, 2013).

La situación en el Medio Oriente y en el sudeste de Asia se ha propagado a países como Iraq que sostiene una cifra de 2`100.000, Siria con 6`500.000 y Pakistán con 747.000 DI.

$4 \quad$ Es una región situada entre Europa del Este y Asia Occidental, entre el Mar Negro y el Mar Caspio. 
El contexto americano se ve reflejado por países como México, Honduras, Perú y Colombia, este último ocupaba en 2013 el primer puesto con el mayor número de desplazados internos del mundo con un entre 4'900.000 y 5'500.000, cifra que al día de hoy se mantiene según un último informe del IDMC (IDMC, 2013).

Para el caso de Colombia, la situación es alarmante debido a que en el presente somos el segundo país con mayor cantidad de desplazados internos como consecuencia del conflicto armado y la violencia generalizada y sostenemos el primer puesto de desplazados internos en el continente americano según el IDMc. Esto lleva a realizarse una serie de preguntas: ¿cuáles son las circunstancias del conflicto que han conducido al país a ser de los principales países con mayor número de desplazados internos?, ¿qué políticas y normatividad se han hecho para buscar una solución al desplazamiento interno? lo que conlleva a desarrollar la índole de la problemática social en Colombia y por ende a establecer cuáles son los factores que determinan el conflicto.

\section{¿Cuáles son los factores que determinan el desplazamiento en Colombia?}

El conflicto armado interno que se presenta en Colombia ha tenido distintas dimensiones sociales, económicas y culturales, presentándose así, como consecuencia de ello, una violación de los derechos humanos permanentemente.

Aquellos factores que determinaron el éxodo de la población civil se deben a la estrategia de expansión territorial de los grupos paramilitares, las deficiencias en los procesos de desmovilización (Ley 975 de 2005), el reagrupamiento y rearme de algunos hombres de desmovilizados, la ofensiva militar de recuperación territorial del Estado en cumplimiento 
de la política de seguridad democrática, la siembra masiva e indiscriminada de minas antipersonales por parte de las FARC (Análisis extraídos del Centro Nacional de Memoria Histórica-CNMH-, 2013, p. 71).

Del progreso de los factores señalados se desembocan algunas consecuencias desarrolladas con el transcurso de los años, tales como son los rezagos propiciados por el narcotráfico, los intereses provenientes de sectores empresariales y la consecuencia ambiental proveniente del mal manejo de las tierras por parte de grupos al margen de la ley, de empresas y de la minería tanto legal como ilegal. ${ }^{5}$

\section{Margen del desplazamiento histórico en Colombia}

Existen diversas organizaciones gubernamentales y no gubernamentales que se han encargado de llevar la tarea de la recopilación de información para plasmarla en diferentes estadísticas. El Registro Único de Víctimas (en adelante, RUV) de la Unidad para la Atención y Reparación Integral de Víctimas y la Consultoría para los Derechos Humanos y el Desplazamiento (codHes, en adelante) han llevado el proceso para determinar las cifras pertinentes.

El proceso para determinar las cifras ha tenido distintas divergencias y diferentes problemáticas, dado que las cifras que emite el Ruv, el codHes y distintas organizaciones no

5 En este punto cabe resaltar el estudio de Oscar A. Alfonso (2011) en el cual señala que una de las circunstancias de agravación del desplazamiento se desprende del conflicto y la connotación ambiental que desarrollan algunos terrenos en el país, expresa : "en primer lugar, que la tierra de mejor calidad se encuentra controlada por poderes que no le es factible enfrentar o quienes sostienen vínculos indisolubles y, en segundo lugar, que muy probablemente esa tierra haya entrado en una fase de degradación que afecte su fertilidad por la extralimitación de su explotación, la mecanización, y el uso indiscriminado de fertilizantes que agotó el humus”. 
coinciden entre sí, pero las diversas fuentes de información sí convergen en que el desplazamiento forzado es una modalidad de violencia que ha tenido su incremento o escalada a partir del año 1996.

El reconocimiento por parte del Estado ha sido uno de los puntos que han retrasado el conflicto, ello se evidencia en que hasta el año 1997 el gobierno nacional emitió la Ley 387, con la cual se dio inicio a un registro oficial de datos (CNMH, 2013, p. 71), y estuvo parcialmente reglamentada hasta el año 2000 con el Decreto 2569.

La gravedad e incidencia del conflicto han tenido también consecuencias económicas y políticas, al punto de que en el vivir diario de la agenda pública este sea uno de los puntos importantes. Siguiendo el estudio de Brenda Pérez, a partir de la Ley 387 se comenzó a analizar la gravedad del desplazamiento con lo cual desde el año 1997 se crearon organizaciones e instituciones de gran importancia para la observación del conflicto "como el Sistema Nacional de Atención Integral a la Población Desplazada por la Violencia, el Plan Nacional para la Atención Integral a la Población Desplazada por la Violencia y el Programa Nacional de Atención Integral a la Población Desplazada por la violencia”(Pérez, 2014, p. 10).

La discrepancia de las cifras se logra evidenciar por la diferencia perceptible en la cantidad de desplazados internos, esta es presentada por las distintas fuentes y las diferentes metodologías empleadas para realizar los estudios de manera diversa: el RUV reportó 4'774.046 desplazados internos y el codHes estima 5'700.000 desplazados internos, del cual estima que para el periodo de 1985-1995 hubo un total de 819.510 víctimas de este delito de lesa humanidad. Se hace énfasis en el periodo 1985-1995 ya que el coDHes se creó en 1992 y sus trabajos comenzaron a emplearse a partir de 1995, 
que para sus análisis implementa el "Sistema de Información sobre Desplazamiento Forzado y derechos Humanos sidHes ${ }^{6}$ (Piñeros, 2012, p. 173)

Tal vez el caso más representativo del problema para diferenciar las cifras es el hecho que se presenta al decir que tres de cada diez hogares no reciben ayuda del Estado dado que no se encuentran registrados o están tramitando dicho registro (Piñeros, 2012, p. 10). El registro que mantiene el RUV no tiene cobertura general y universal del total de las víctimas del conflicto, lo que como consecuencia lleva a que se evidencie la falta de cubrimiento en que incurre el gobierno para resolver este fenómeno social. Desde 1997 se han emprendido esfuerzos para encontrar una solución frente a esta problemática, pero, siguiendo a la Corte Constitucional en Sentencia T025/04 (M.P.: M. J. Cepeda), la falta de acción ha constituido un problema grave dado que el registro de las víctimas ha sido tardío, lo que se evidencia en

[...] los niveles de cobertura de todos los componentes de la política son insuficientes. La atención humanitaria de emergencia, es el componente que mejores resultados ha registrado entre 1998 y 2002 tuvo una cobertura del 43\% de hogares desplazados registrados por la Red de Solidaridad Social, del 25\% de familias reportadas por coDHes, y ha cumplido con el 36\% del nivel establecido como meta en el Plan Estratégico. Al analizar únicamente los casos de desplazamiento individual, se observa que los datos son peores. En este caso, la cobertura es del 33\% de los despla-

6 El cual es un instrumento de estimación y caracterización socio-demográfica de la población desplazada que opera desde 1995 bajo la responsabilidad de CODHES. 
zados registrados por la Red de Solidaridad Social, y del $15.32 \%$ de los reconocidos por codHes (2004).

\section{Distribución del desplazamiento por regiones en Colombia} El conflicto armado en Colombia ha tenido y mantiene diferentes actores en el transcurso de su historia y estos han venido cambiando en las diferentes décadas, como: grupos guerrilleros, grupos paramilitares, la fuerza pública, grupos no reconocidos al margen de la ley, entre otros, a los cuales se les atribuyen diferentes delitos de lesa humanidad, como lo es el desplazamiento forzoso. Esta práctica también ha tenido diferentes actores que la propagan de manera continua, sistemática y selectiva. Los grupos armados (combatientes) a los que se les atribuye esta práctica de manera continua, permanente y como medio para imponer su poder son los grupos guerrilleros y las bandas organizadas que se originaron después del proceso de desmovilización de los grupos paramilitares. Los primeros recurriendo a desplazamientos forzados de manera selectiva y los segundos, a desplazamiento forzados de manera masiva.

El país y en general la zonas rurales del país han evidenciado una práctica conocida como "tierra arrasada" la cual “consiste en el ejercicio de la violencia que no solo aniquila a las personas, sino que destruye el entorno material y simbólico de las víctimas. De esta manera el territorio se vuelve inhabitable por la propagación de las huellas de terror, lo que fuerza al éxodo de la población" (CNMH, 2013, p. 73). Práctica que como consecuencia trae el abandono parcial o total de la población, permitiendo acoger estos lugares como puntos estratégicos para los diferentes actores de conflicto. El desplazamiento forzado recoge un total de 5'700.000 víctimas provenientes de lugares como Santa Marta, Turbo, Apartadó, El Carmen del Bolívar, Medellín, Riosucio, Buenaventura, 
San José del Guaviare, Tumaco, Puerto Asís, Tame, Tierralta, Tibú y Valledupar.

El Ruv establece que del año 1996 al 2002 hubo un aproximado de 2’014.893 desplazados, y de igual manera se presentó una suma anual entre el año 2000 al 2003 que superó las 300.000 personas. Para la fecha, la cifra aproximada es de 77.000 Di (RUv, 2014).

Para mayo de 2104 los departamentos más afectados con la recepción de desplazados son Bogotá, con 14.630; Valle del Cauca con 13.764; Antioquia con 10.671; Nariño con 9.029 y Cauca con 6.550 DI (RUv, 2014); lo cual reivindica la eventual preferencia de los desplazados internos a recurrir a trasladarse a las ciudades principales del país (Alfonso, 2011, p. 4). ${ }^{7}$

Son 1.116 municipios que registraron la expulsión de la población como consecuencia del conflicto armado, lo que representa un $97 \%$ del territorio nacional, a pesar de ello, el fenómeno no afectó por igual los distintos territorios ya que 139 municipios registraron más de 10.000 desplazados entre 1996 y 2012, lo que equivale al 74\% de la población desplazada, otros 57 municipios registraron más de 20.000 , otros 26 municipios mostraron más de 30.000, 12 municipios más reportaron más de 40.000 y nueve municipios más con 50.000 desplazados (CNMH, 2013, p. 76).

\section{Proyección de la situación actual}

Desde el año 1996 hasta el 2002 el desplazamiento en Colombia tuvo un incremento de sus cifras lo que ha llevado a que en

$7 \quad$ Al finalizar 2009 se registraron 3’303.970 personas desplazadas por los violentos a cambiar de lugar de residencia, de los cuales el 29\% de los desplazados había migrado dentro del mismo municipio, mientras que el 71\% se dirigió a lugares más lejanos del lugar de origen de sus municipios, específicamente hacia la capital. Esta eventual preferencia se reivindica con las cifras actuales del RUv. 
2004 la Corte Constitucional por medio de la ya mencionada Sentencia T 025-04 haya referido a la existencia de un "estado de cosas inconstitucional". Durante esta fase se presentaron dos tipos de desplazamiento, el primero que es el desplazamiento forzado individual, que comprendió el 73\% del total de desplazados, y el denominado desplazamiento forzado masivo, que abarcó el 27\% restante (cNMH, 2013, p. 74).

Sin embargo, alrededor del 60\% de los desplazados internos provienen de las áreas rurales del país y en muchos casos estas personas no han tenido la oportunidad de haber estado en otras ciudades del país. Algunos estudios sobre el desplazamiento interno en Colombia utilizan el sistema conocido como índice de calidad de vida, el cual se emplea para evaluar aquellas condiciones de vida de la población afectada y lo comparan con el estándar mínimo de vida constitucional (Piñeros, 2012, p. 177). En este caso se ven por debajo del promedio.

Una de las características que desarrolla esta modalidad de violencia radica en que la población más afectada resultan ser los niños, las mujeres, los adultos mayores de edad, los pueblos indígenas y afro colombianos (codHes, 1999). Aquí se constata que el promedio de edad de las personas desplazadas que parten de sus lugares de origen de manera individual es de un promedio de 23 años (Carrillo, 2009, p. 530).

Las estadísticas no producen una grata sensación debido a ciertos factores como la cobertura de la educación, la salud y la falta de trabajo (Piñeros, 2012, p. 194). ${ }^{8}$ Gracias a algunos estudios se observa que

8 Por otro lado y de conformidad con lo expresado por la Corte Constitucional, la cobertura se ha visto estancada, pero también su sostenibilidad en el tiempo como lo señala Piñeros Mendoza en su estudio, en el cual señala: "hay retroceso en el cumplimiento en alguno de los derechos analizados al menos en el 20\% de los 
[...] las personas provenientes del conflicto armado, presentan un déficit educativo y académico, dado que las estadísticas propuestas informan lo siguiente: el 11\% de los desplazados no tienen educación, el 2\% tienen estudios técnicos o profesionales (o al menos cursado un año), el $40 \%$ no completó su primaria básica de educación, el 25\% sostiene estudios de bachillerato (al menos un año), y el $22 \%$ restante completo la primaria básica de educación.

Estas estadísticas fueron realizadas a la población vulnerable en calidad de mayoría de edad (Carrillo, 2009, p. 535). La educación constituye un aspecto determinante para la obtención de un trabajo digno y con una justa remuneración, que, de tener más cobertura, se propiciarían mejores condiciones de vida para los desplazados por el conflicto.

Frente a la pobreza en cabeza de los desplazados, los estudios arrojan como resultado que la población desplazada se encuentra en situación de pobreza y en algunos casos de pobreza extrema. Según las diferentes fuentes, la capital ha tenido gran acogida por parte de los desplazados, pero también es evidente el crecimiento de la pobreza y de la falta de empleo para las víctimas del conflicto. Existe un empeoramieno en los hogares de las familias desplazadas, ello en cuanto a que "el 83\% de los desplazados estaría en condición de indigencia. Según el mismo estudio el 10\% de los hogares desplazados deben

hogares; el mayor retroceso se presenta en los derechos a la salud (39\%), la alimentación (38\%) y la generación de ingresos (36\%), lo que confirma que son los menos sostenibles en la política de atención a los desplazados", como objetivos de la Ley 387 de 1997 se encuentra lo que es la asistencia humanitaria y la estabilidad económica de los desplazados. El objeto de la ley no ha tenido un desarrollo óptimo frente a estas situaciones ya que no representa una garantía a la dignidad y de los derechos fundamentales a este grupo afectado de personas. 
enviar a sus niños y adolescentes (7 años a 17 años) a trabajar, y que por lo menos en el 17\% de las familias desplazadas se encontraba una mujer en embarazo" (Piñeros, 2012, p. 194). Por otra parte se encuentran las grandes falencias que han tenido las diferentes políticas implementadas por los distintos periodos presidenciales, no solamente frente a la cobertura de los planes de gobierno, sino de su inclusión social, los índices de protección y cobertura de derechos fundamentales como educación y salud, entre otros, no han tenido una satisfacción integral a esta población afectada, específicamente a la mujer, la niñez y la adolescencia, y esto se presenta en cuanto a las notables diferencias que mantenían los distintos registros, y las víctimas que se conocían.

Es pertinente traer a colación las cifras dadas en cuanto a quienes son cabeza de familia: siguiendo el análisis de Internal Displacement in Colombia: Humanitarian, Economic and Social Consequence in Urban Settings and Current Challenges", las cifras de quienes son cabezas de familia se distribuyen de la siguiente manera: el 51,2\% son hombres cabeza de familia, el 39,2\% son personas que se sostienen individualmente y el 9,6\% son mujeres cabeza de familia (Carrillo, 2009, p. 539).

\section{Conclusiones parciales}

Podríamos concluir de esta parte de la investigación cuál es la posición que mantiene Colombia en la actualidad, de la mano de los índices internacionales sobre desplazamiento interno, que no es alentadora visto desde una perspectiva en relación con otros Estados. Acorde con las cifras del IDMc, entre los países más afectados por el desplazamiento en Latinoamérica encontramos a México y Guatemala, ello se debe a distintos factores, sin embargo las cifras de estos dos países no superan el 10\% que tiene Colombia. Entre los factores más relevantes 
que ha tenido el país es el hecho de que un $27 \%$ de los desplazamientos internos en Colombia (CNMH, 2013) se haya dado de forma masiva; y por otro lado, está la situación de que aquí las víctimas del desplazamiento forzoso prefieran desplazarse a las ciudades principales del país. Estas dos situaciones hacen la problemática del desplazamiento uno de los problemas más perceptibles en la sociedad y en los medios de comunicación. Todo lo contrario a lo que sucede en los demás países del continente americano, dado que, si se presenta el desplazamiento, este se da en formas y cantidades diferentes a las que se presentan en Colombia. ${ }^{9}$

Esta situación debe convertirse en uno de los puntos más importantes a tratar de ahora en adelante, el hecho de que Colombia ostente una cifra de 4'900.000 a 5'500.000 millones de personas víctimas por esta modalidad empleada por los grupos armados da a entender la magnitud del conflicto y la falta de intervención estatal en la que haya podido incurrir el Estado desde 1985 a la actualidad.

\section{Segunda parte. Condenas de la Corte Interamericana de Derechos Humanos por desplazamiento forzado en Colombia}

Habiendo ya definido desplazamiento forzado y con ello la posición de Colombia a nivel internacional en relación a las cifras de desplazamiento mundial, se procederá a hacer un

\footnotetext{
9 Basta con observar algunos casos como los sucesos presentados en San Carlos o El Salado, Bolívar, en los cuales se presentaron desplazamientos forzosos a través del mencionado desplazamiento masivo; el Grupo de Memoria Histórica registro un abandono parcial o total de 54 de 74 veredas en el Municipio de San Carlos y, en el caso de El Salado, un abandono durante dos años por parte de sus habitantes (cnmh, 2013). Estos casos demuestran la diferencia abismal que existe con otros países, y más con los países latinoamericanos.
} 
análisis sobre condenas de la Corte Interamericana de Derechos Humanos (en adelante, Corte IDH) contra Colombia, basándonos en un método mixto entre análisis de caso y una metodología descriptiva sobre la circunstancia en concreto.

Lo importante aquí es medir el nivel de cumplimiento de Colombia respecto de las órdenes dictadas por la Corte IDH en relación con los casos que han sido objeto de investigación, para ello al final del análisis descriptivo realizaremos una tabulación de la información obtenida presentando así los resultados sobre el cumplimiento de las órdenes dictadas a Colombia sobre desplazamiento forzado aproximadamente desde el año 2004.

\section{Caso de la masacre de Mapiripán vs. Colombia (Corte IDH, 2005) $)^{10}$}

En el año de 1997 el Municipio de Mapiripán, en el Departamento del Meta, fue abatido por una serie de asesinatos, torturas y masacres a lo que se le conoció como "la masacre de Mapiripán”, en que, de acuerdo con los relatos de las víctimas y los hechos aceptados por la Corte IDH, paramilitares en colaboración de las fuerzas militares de nuestro país permitieron el acceso al municipio para proceder a asesinar a civiles inocentes, que según lo narrado se creía eran colaboradores de la guerrilla colombiana. ${ }^{11}$

10 Se relaciona la fecha en que tuvieron lugar los hechos de la masacre de Mapiripán, aceptados por el Estado colombiano y por la Corte Interamericana de Derechos Humanos en sentencia de la Corte Interamericana de Derechos Humanos Masacre de Mapiripán, con fecha 5 de septiembre de 2005.

11 Este caso fue llevado ante la Corte IDH el 15 de septiembre de 2005 (ocho años después de la masacre) por las graves violaciones de derechos humanos causadas en medio del conflicto armado interno en Colombia, que lamentablemente aún están vigentes. Además, es uno de los primeros casos en los cuales la Corte IDH 
La Corte IDH condena a Colombia por este caso en razón de que los pobladores afectados por el desplazamiento puedan regresar regresar o retornar a sus hogares en condiciones de seguridad (Corte IDH, Colombia, 2004), ${ }^{12}$ actualmente el caso es objeto de estudio mediante Resolución de la Corte IDH, se mantiene bajo supervisión de cumplimiento como uno de los puntos pendientes de acatamiento.

La Corte IDH $^{13}$ basa su declaración en lo contenido en la Sentencia T-025 de 22 de enero de 2004, emitida por la Sala Tercera de Revisión de la Corte Constitucional, así como en un informe emitido por el Ministerio de Defensa Nacional de la República de Colombia y también en un informe de la Alta Comisionada de las Naciones Unidas para los Derechos $\mathrm{Hu}^{-}$ manos sobre la situación de los derechos humanos en Colombia, y enfatiza que es necesario brindar una ayuda primordial a madres que son cabeza de familia y a través de mecanismos efectivos como leyes o políticas públicas que se implementen y generen un avance con relación a esta situación. Así pues, en conjunto con la Sentencia T-025 de 2004 que ordena al Estado colombiano a brindar una colaboración íntegra a las personas víctimas de desplazamiento forzado, la Corte IDH basa sus condenas persiguiendo el mismo fin que es resarcir

condena por desplazamiento forzado y sirve como base para manifestarse sobre otras decisiones que ha tomado respecto de este tema.

12 Sentencia de la Corte Interamericana de Derechos Humanos Masacre de Mapiripán de 5 de septiembre de 2005,p 181: “E1 Estado deberá realizar las acciones necesarias para garantizar las condiciones de seguridad para que los familiares de las víctimas, así como otros ex pobladores de Mapiripán, que se hayan visto desplazados, puedan regresar a Mapiripán, en caso de que así lo deseen, en los términos de los párrafos 311 y 313 de [la] Sentencia”. Recuperado de http://www.corteidh.or.cr/ docs/casos/articulos/seriec_134_esp.pdf

13 Ibíd. 
los daños causados por el conflicto armado interno y prevenir posibles situaciones de riesgo para el Estado.

\section{Caso masacre de Pueblo Bello vs. Colombia} (Corte IDH, 2006) $)^{14}$

Otro de los casos por desplazamiento forzado se dio a principios de la década de 1990, cuando un grupo de 60 hombres pertenecientes a grupos paramilitares llegaron al corregimiento de Pueblo Bello con el fin de realizar un ataque. Estando allí, y con lista en mano de las personas que consideraron "sospechosas", decidieron ingresar a las viviendas, desalojarlas y llevarse a los hombres que habitaban las mismas, secuestrándolos con la única finalidad de acabar con sus vidas en la plaza principal del corregimiento, logrando de esta forma sembrar miedo y terror entre los pobladores de la zona. ${ }^{15}$

El caso llega ante la Corte IDH el 23 de marzo de 2004 y, en Sentencia del 31 de enero de 2006, la Corte resuelve sobre el caso materia de estudio en donde especifica que, debido a que algunos de los casos desplazamiento forzado se presentan con posterioridad a la demanda ${ }^{16}$ presentada ante la Comisión IDH, la Corte no conocerá y no procederá a analizar las situaciones en relación con esas víctimas.

Debido a lo anterior, la Corte IDH en sus Resoluciones de Supervisión de Cumplimiento, establece que ha realizado un

14 Sentencia de la Corte IDH en relación a la masacre de Pueblo Bello, fecha de 31 de enero de 2006. Recuperado de http://www.corteidh.or.cr/docs/casos/articulos/ seriec_140_esp.pdf.

15 Respecto de esta sugerencia, si revisáramos los alegatos de este caso tendríamos por ende que revisar los alegatos de los demás casos y el tema sería mayor.

16 Demanda originada en las denuncias no 10566 y 11748 recibidas en la Secretaría de la Comisión el 12 de febrero de 1990 y 5 de mayo de 1997. Corte IDH, Caso de la masacre de Pueblo Bello vs. Colombia, Sentencia de 31 de enero de 2006. 
seguimiento primordialmente a la orden de brindar un tratamiento médico adecuado, haciendo necesaria la vinculación a algún tipo de sistema de salud colombiano. Respecto de la Orden de Garantía de Seguridad a los habitantes para que regresen a Pueblo Bello, la Corte no ha emitido un seguimiento en el cual establezca la situación actual de esas personas víctimas de desplazamiento forzado, toda vez que ha requerido al Estado información actualizada del mismo.

\section{Caso de las masacres de Ituango vs. Colombia (Corte IDH, 2007) ${ }^{17}$}

Esta situación de conflicto armado se presentó en los corregimientos de El Aro y La Granja en el departamento de Antioquia, en donde los grupos paramilitares o autodefensas, conocidas como AUc, con ayuda de fuerzas militares, quienes mostraron conductas omisivas, ingresaron a estos corregimientos, generando terror y caos, despojando a los pobladores de sus posesiones y obligándolos a desplazarse de esta región.

Las circunstancias de violencia generadas en las masacres de Ituango son otras de las causales por las cuales se condena al Estado colombiano en razón del desplazamiento forzado. La Corte IDH estableció en dicha condena ${ }^{18}$ que el Estado violó el artículo 22 de la Convención del Derecho de Circulación

17 Sentencia de la Corte IDH, caso de las masacres de Ituango vs. Colombia, Sentencia de 1 de julio de 2006. Recuperado de http://www.corteidh.or.cr/docs/ casos/articulos/seriec_148_esp.pdf

$18 \quad$ Ibíd., p. 147: "E1 Estado violó, en perjuicio de las personas desplazadas de E1 Aro y La Granja, quienes se encuentran señaladas en los párrafos 225 y 235 de esta Sentencia, el derecho de circulación y de residencia, consagrado en el artículo 22 (Derecho de Circulación y de Residencia) de la Convención, en relación con el artículo 1.1 (Obligación de Respetar los Derechos)". 
y Residencia luego de que la misma Corte realizara una interpretación sustancial de dicha norma.

La Corte IDH en su última Supervisión de Cumplimiento dice que este es un punto pendiente de acatamiento, hasta que el Estado no dé un Informe de Satisfacción respecto de la Orden. ${ }^{19}$

\section{Caso Valle Jaramillo vs. Colombia (Corte IDH, 2008) ${ }^{20}$}

El defensor de los derechos humanos Jesús María Valle Jaramillo a partir del año 1996, desde su oficina en Medellín, comenzó a realizar denuncias de actividades de grupos paramilitares en la zona, particularmente en el municipio de Ituango. En razón de ello el 27 de febrero de 1998 dos hombres ingresaron abruptamente a su oficina y le dispararon, causándole la muerte instantánea. En el lugar de los hechos se encontraban Nelly Valle Jaramillo y Carlos Fernando Jaramillo Correa, quienes fueron amarrados y amenazados con armas de fuego, viéndose obligado este último junto a su núcleo familiar a, inicialmente, desplazarse dentro de Colombia, para posteriormente exiliarse en el exterior, como consecuencia de las amenazas y hostigamientos recibidos, ya que era testigo

19 En cuanto a la obligación de realizar las acciones necesarias para garantizar las condiciones de seguridad para que los ex habitantes de los corregimientos de El Aro y La Granja que se hayan visto desplazados puedan regresar, según sea el caso y si así lo desearan, el Estado informó que la Alta Dirección de la Agencia Presidencial para la Acción Social constituyó el Equipo de Derechos Humanos y DiH para atender a la prevención y atención integral del desplazamiento forzado interno y que Acción Social ha implementado el "Sistema de Atención a Población Desplazada, Red Nacional de Juntos y Retornar es Vivir” Sentencia de la Corte IDH. Recuperado de http://www.corteidh.or.cr/docs/supervisiones/masacres_21_05_13.pdf

20 Sentencia de la Corte IDH, caso Valle Jaramillo y otros vs. Colombia, Sentencia de 27 de noviembre de 2008. Recuperado de http://www.corteidh.or.cr/docs/ casos/articulos/seriec_192_esp.pdf 
de los hechos ocurridos el 27 de febrero de 1998, y que el Estado lo había puesto en una situación de desprotección y vulnerabilidad.

La Corte acepta el reconocimiento de responsabilidad internacional efectuado por el Estado,y manifiesta que existió violación del derecho de circulación, reconocido en el artículo 22.1 de la Convención Americana sobre Derechos Humanos, en relación con la obligación general de garantía contemplada en el artículo 1.1 de la misma, en perjuicio de Carlos Fernando Jaramillo Correa, su cónyuge Gloria Lucía Correa, su hijo Carlos Enrique Jaramillo Correa y sus hijas, María Lucía Jaramillo Correa y Ana Carolina Jaramillo Correa, en los términos del párrafo 144 de esta Sentencia. ${ }^{21}$

La última resolución de la Corte $\mathrm{IDH}^{22}$, que trata sobre la obligación del Estado de garantizar la seguridad en caso de que Carlos Fernando Jaramillo Correa considere su retorno a Colombia, es la dictada el 28 de febrero de 2011. En esta se declara que la mencionada obligación aún queda pendiente de acatamiento, debido a que las víctimas, a través de sus representantes, consideraron que "las razones que hacen temer por la vida de las víctimas aún subsisten, y que el Estado no ha tomado medidas efectivas para transformar de manera real las difíciles condiciones que existen en el municipio de Ituango".

21 Para la Corte "el derecho de circulación y de residencia puede ser vulnerado por restricciones de facto si el Estado no ha establecido las condiciones ni provisto los medios que permiten ejercerlo".

22 Resolución de Cumplimiento, Corte IDH, caso Valle Jaramillo vs. Colombia, 28 de febrero de 2011. Recuperado de: http://www.corteidh.or.cr/docs/supervisiones/jaramillo_28_02_11.pdf 


\section{Caso Manuel Cepeda Vargas vs. Colombia (Corte IDH, 2010) ${ }^{23}$}

El caso hace referencia a la ejecución extrajudicial del que para entonces era senador de la república y líder político, el Señor Manuel Cepeda Vargas, en razón de la ola de masacres sobre determinados grupos políticos de la época de los años 1990.

El caso fue presentado ante la Comisión IDH en el año 2008 y fue decidida en Sentencia de Fondo para 2010, en donde se establecieron determinadas órdenes, una de ellas en relación con un alegado desplazamiento forzado por las condiciones de seguridad que se debían garantizar a los familiares de la víctima.

La Corte IDH dicta: ${ }^{24}$ "El Estado debe adoptar todas las medidas necesarias para garantizar la seguridad de los familiares del Senador Manuel Cepeda Vargas, y prevenir que deban desplazarse o salir del país nuevamente como consecuencia de actos de amenazas, hostigamiento o de persecución en su contra con posterioridad a la notificación de esta Sentencia”.

\section{Caso masacre de Santo Domingo vs. Colombia (Corte IDH, 2012) ${ }^{25}$}

Los hechos sucedidos en esta masacre datan del 13 de diciembre 1998, en una vereda de Arauca llamada Santo Domingo, donde en medio de un operativo militar desarrollado por las Fuerzas Militares en conjunto con la Fuerza Aérea Colom-

23 Sentencia Corte IDH, caso Cepeda Vargas vs. Colombia, Sentencia de 26 de mayo de 2010. Recuperado de: http://www.corteidh.or.cr/docs/casos/articulos/ seriec_213_esp.pdf

24 Ibíd. Puntos Resolutivos.

25 Sentencia Corte IDH, caso masacre de Santo Domingo vs. Colombia, Sentencia de 30 de noviembre de 2012. Recuperado de: http://www.corteidh.or.cr/ docs/casos/articulos/seriec_259_esp.pdf 
biana, cuya finalidad era decomisar la carga de un avión que aterrizó en la carretera cercana a la vereda, presumiblemente con dinero o armas destinadas al narcotráfico, estos fueron interrumpidos por disparos realizados por armas de largo alcance accionadas por la guerrilla. Al siguiente día, miembros del Ejército, que se encontraban a bordo de helicópteros, comenzaron a disparar contra las personas que estaban en la vereda, incluyendo la población civil, bombardeos que produjeron, además de muertes, daños a los bienes inmuebles. Esta situación llevó a que la población restante abandonara sus casas y se desplazara hacia poblaciones cercanas.

La Corte IDH considera que existió una violación al Artículo 22 de la Convención Americana de Derechos Humanos en razón de que la libre circulación hace parte del libre desarrollo de la personalidad y contribuye a una formación progresiva de las comunidades y es a través de esta disposición que se protege a las personas que han sido víctimas del desplazamiento forzado.

Sin embargo, pese a la violación cometida, el Estado resarció en gran parte los daños causados, reconstruyendo la población de Santo Domingo y prestando la ayuda necesaria a las personas que fueron obligadas a desplazarse del corregimiento. Actuación que es valorada por la Corte IDH aunque falta la identificación de ciertas víctimas y familias que por razones de seguridad y protección a sus vidas no han retornado a Santo Domingo, esto establecido en la Sentencia de Fondo, ya que la Corte IDH no se ha pronunciado en Resolución de Supervisión de Cumplimiento. 
Caso de las comunidades afrodescendientes desplazadas de la cuenca del río Cacarica (Operación Génesis) vs. Colombia (Corte IDH, 2013) ${ }^{26}$

La situación fáctica vivida en este caso es la incursión de Grupos Paramilitares o de Autodefensas Unidas de Colombia realizada a la cuenca del río Cacarica, donde habitan comunidades afrodescendientes y ancestrales que para la época eran poseedoras de estos territorios colectivos, en que, debido a las violentas confrontaciones entre varios grupos armados, se produjo un desplazamiento masivo de estas comunidades.

Según cifras registradas en la Defensoría del Pueblo (1997), ${ }^{27}$ más de 15.000 personas fueron desplazadas de la zona del Bajo Atrato Chocoano. Es precisamente debido a su ubicación estratégica que los grupos armados ilegales se disputan este territorio y como consecuencia de ello se produce este desplazamiento forzado.

La Corte IDH ${ }^{28}$ responde que el Estado colombiano es responsable en razón de una omisión ya que, viendo la situación presentada, no existió una manifestación inmediata para generar condiciones de seguridad a la población víctima de los ataques y que por tanto se vulneraron los Derechos establecidos en la Convención Americana de Derechos Humanos (Derecho de Circulación y Residencia) y su obligación de garantizar los derechos a la integridad personal y a no ser desplazados forzadamente.

26 Sentencia de Fondo de la Corte IDH, caso “Operación Génesis”vs. Colombia, con fecha 20 de noviembre de 2013. Recuperado de http://www.corteidh.or.cr/ docs/casos/articulos/seriec_270_esp.pdf

27 Ibíd., p. 35.

28 Ibíd., p. 104. 
Análisis gráfico. Reflexión y resultado de la investigación

\begin{tabular}{|c|c|}
\hline Nombre del caso & Masacre de Mapiripán. Gráfico n ${ }^{\circ} 1$ \\
\hline $\begin{array}{l}\text { Fecha de Sentencia } \\
\text { de Fondo }\end{array}$ & 15 de septiembre de 2005 \\
\hline Órdenes & $\begin{array}{l}\text { 1. Investigación por parte del Estado de los hechos del caso, } \\
\text { identificar, juzgar y sancionar a los responsables de la masacre } \\
\text { 2. Identificación de las víctimas de la masacre de Mapiripán y } \\
\text { sus familiares } \\
\text { 3. Mecanismo oficial de seguimiento del cumplimiento de las } \\
\text { reparaciones ordenadas } \\
\text { 4. Tratamiento adecuado a los familiares de las víctimas } \\
\text { 5. Garantías estatales de seguridad para los ex habitantes del } \\
\text { municipio de Mapiripán que decidan regresar } \\
\text { 6. Disculpa pública y reconocimiento de responsabilidad, a } \\
\text { nivel internacional } \\
\text { 7. Monumento } \\
\text { 8. Educación en derechos humanos para las Fuerzas Militares } \\
\text { 9. Publicación de las partes pertinentes de la sentencia }\end{array}$ \\
\hline $\begin{array}{l}\text { Sentencias de } \\
\text { Supervisión de } \\
\text { Cumplimiento }\end{array}$ & $\begin{array}{l}\text { - } \quad 8 \text { de julio de } 2009 \\
\text { - } \quad 8 \text { de febrero de } 2012 \\
\text { - } \quad 23 \text { de noviembre de } 2012\end{array}$ \\
\hline $\begin{array}{l}\text { Última Supervisión } \\
\text { de Cumplimiento }\end{array}$ & 23 de noviembre de 2012 \\
\hline $\begin{array}{l}\text { Cumplimiento } \\
\text { ITotal (CT) } \\
\text { II Parcial (CP) } \\
\text { III No hay } \\
\text { cumplimiento NC) }\end{array}$ & $\begin{array}{l}\text { 1. Órdenes } \mathrm{n}^{\circ} \text { 1,2, 4, 5,7: Se mantiene abierto el } \\
\text { procedimiento de Supervisión de Cumplimiento sobre los } \\
\text { puntos pendientes de acatamiento. (NC) } \\
\text { 2. Órdenes } n^{\circ} 3,6,8,9 \text { : La Corte IDH estima que se ha dado } \\
\text { un pleno cumplimiento (CT) }\end{array}$ \\
\hline
\end{tabular}

Nota: Lo resaltado en negrilla corresponde a las órdenes dictadas por la Corte IDH en relación con el desplazamiento forzado, en los casos de grupo se plantea una Orden de Garantías Estatales de Seguridad, en los casos particulares se manifiesta una orden de prevención a las personas que, en razón de la situación de conflicto presentada se vean amenazados o puedan llegar a ser víctimas al igual que sus familiares.

\begin{tabular}{|l|l|}
\hline \multicolumn{1}{|c|}{ Nombre del caso } & \multicolumn{1}{|c|}{ Pueblo Bello Gráfico n $^{\circ}$} \\
\hline $\begin{array}{l}\text { Fecha de Sentencia } \\
\text { de Fondo }\end{array}$ & 31 de enero de 2006 \\
\hline Órdenes & $\begin{array}{l}\text { 1. Investigación por parte del Estado de los hechos del caso, } \\
\text { identificación, juicio y sanción de los responsables }\end{array}$ \\
\hline
\end{tabular}




\begin{tabular}{|c|c|}
\hline Nombre del caso & Pueblo Bello Gráfico n ${ }^{\circ} 2$ \\
\hline Órdenes & $\begin{array}{l}\text { 2. Búsqueda, identificación y sepultura de las víctimas de la } \\
\text { masacre de Pueblo Bello } \\
\text { 3. Tratamiento médico o psicológico adecuado a los familiares } \\
\text { 4. Garantías estatales de seguridad para los familiares y ex } \\
\text { habitantes del municipio de Pueblo Bello que decidan regresar } \\
\text { 5. Disculpa pública y reconocimiento de responsabilidad } \\
\text { internacional } \\
\text { 6. Monumento } \\
\text { 7. Publicación de las partes pertinentes de la presente Sentencia }\end{array}$ \\
\hline $\begin{array}{l}\text { Sentencias de } \\
\text { Supervisión de } \\
\text { Cumplimiento }\end{array}$ & $\begin{array}{l}\text { - } \quad 26 \text { de febrero de } 2008 \\
\text { - } \quad 8 \text { de febrero de } 2012\end{array}$ \\
\hline $\begin{array}{l}\text { Última Supervisión } \\
\text { de Cumplimiento }\end{array}$ & 8 de febrero de 2012 \\
\hline $\begin{array}{l}\text { Cumplimiento } \\
\text { ITotal (CT) } \\
\text { II Parcial (CP) } \\
\text { III No hay } \\
\text { cumplimiento (NC) }\end{array}$ & $\begin{array}{l}\text { 1. El Estado ha cumplido con la orden del numeral } 7 \text { (C.T) } \\
\text { 2. En relación con el numeral } 1^{\circ} \text {, la Corte IDH estima que } \\
\text { debido a la falta de información brindada por el Estado sobre } \\
\text { las medidas adoptadas no es posible determinar si se ha dado } \\
\text { cumplimiento o no sobre esta orden } \\
\text { Respecto de las otras órdenes, en las Sentencias de Supervisión } \\
\text { de Cumplimiento la Corte no manifiesta si existe un } \\
\text { cumplimiento parcial o total de las órdenes emitidas, por lo tanto } \\
\text { se infiere que aún no hay cumplimiento (NC) }\end{array}$ \\
\hline Nombre del caso & Masacre de Ituango, Gráfico n ${ }^{\circ} 3$ \\
\hline $\begin{array}{l}\text { Fecha de Sentencia } \\
\text { de Fondo }\end{array}$ & 1 de julio de 2006 \\
\hline Órdenes & $\begin{array}{l}\text { 1. Investigación por parte del Estado de los hechos del caso, } \\
\text { identificación, juicio y sanción de los responsables } \\
\text { 2. Tratamiento adecuado a los familiares de las víctimas } \\
\text { 3. Garantías estatales de seguridad para los ex habitantes del } \\
\text { municipio de Ituango que decidan regresar } \\
\text { 4. Disculpa pública y reconocimiento de responsabilidad } \\
\text { internacional } \\
\text { 5. Programa de vivienda } \\
\text { 6. Placa } \\
\text { 7. Educación en derechos humanos } \\
\text { 8. Publicación de las partes pertinentes de la Sentencia en un } \\
\text { diario de circulación Nacional }\end{array}$ \\
\hline
\end{tabular}




\begin{tabular}{|c|c|}
\hline Nombre del caso & Masacre de Ituango, Gráfico n 3 \\
\hline $\begin{array}{l}\text { Sentencias de } \\
\text { Supervisión de } \\
\text { Cumplimiento }\end{array}$ & $\begin{array}{l}\text { - } \quad 8 \text { de febrero de } 2012 \\
\text { - } 28 \text { de febrero de } 2011 \\
\text { - } 22 \text { de diciembre de } 2010 \\
\text { - } 7 \text { de julio de } 2009\end{array}$ \\
\hline $\begin{array}{l}\text { Última Supervisión } \\
\text { de Cumplimiento }\end{array}$ & 21 de mayo de 2013 \\
\hline $\begin{array}{l}\text { Cumplimiento } \\
\text { I Total (CT) } \\
\text { II Parcial (CP) } \\
\text { III No hay } \\
\text { cumplimiento (NC) }\end{array}$ & $\begin{array}{l}\text { 1. El Estado ha dado pleno cumplimiento a la orden } n^{\circ} 7,8 \\
\text { (CT) } \\
\text { 2. La Corte considera que se ha dado cumplimiento parcial a } \\
\text { las órdenes } n^{\circ} 5,6 \text {. (CP) } \\
\text { La Corte continuará supervisando el cumplimiento pendiente de } \\
\text { las órdenes } \mathrm{N}^{\circ} 1,2,3,4 \text {. (N.C) }\end{array}$ \\
\hline
\end{tabular}

\begin{tabular}{|c|c|}
\hline Nombre del caso & Manuel Cepeda Vargas, Gráfico n ${ }^{\circ} 5$ \\
\hline $\begin{array}{l}\text { Fecha de Sentencia } \\
\text { de Fondo }\end{array}$ & 26 de mayo de 2010 \\
\hline Órdenes & $\begin{array}{l}\text { 1. Investigación por parte del Estado de los hechos del caso, } \\
\text { identificación, juicio y sanción de los responsables } \\
\text { 2. Garantías estatales de seguridad para el retorno a Colombia de } \\
\text { uno de los familiares de las víctimas } \\
\text { 3. Publicación de las partes pertinentes de la Sentencia en un } \\
\text { diario de circulación nacional } \\
\text { 4. Disculpa pública y reconocimiento de responsabilidad a nivel } \\
\text { internacional } \\
\text { 5. Realización de una publicación de un documental } \\
\text { audiovisual oficial acerca de la vida del senador } \\
\text { 6. Brindar una beca con el nombre del Senador Manuel } \\
\text { Cepeda } V \\
\text { 7. Tratamiento médico y psicológico que requieran las víctimas }\end{array}$ \\
\hline $\begin{array}{l}\text { Sentencias de } \\
\text { Supervisión de } \\
\text { Cumplimiento }\end{array}$ & $\begin{array}{l}\text { - } 30 \text { de noviembre de } 2011 \\
\text { - } 8 \text { de febrero de } 2012\end{array}$ \\
\hline $\begin{array}{l}\text { Última Supervisión } \\
\text { de Cumplimiento }\end{array}$ & 08 de febrero de 2012 \\
\hline $\begin{array}{l}\text { Cumplimiento } \\
\text { ITotal (CT) } \\
\text { II Parcial (CP) } \\
\text { III No hay } \\
\text { cumplimiento (NC) }\end{array}$ & $\begin{array}{l}\text { 1. El Estado ha dado pleno cumplimiento a las órdenes n }{ }^{\circ} 3 \text { y } 4 \\
\text { (CT) } \\
\text { Quedan bajo supervisión de cumplimiento de la Corte las } \\
\text { órdenes n } 1,2,5,6 \text { y } 7\end{array}$ \\
\hline
\end{tabular}




\begin{tabular}{|l|l|}
\hline \multicolumn{1}{|c|}{ Nombre del caso } & \multicolumn{1}{|c|}{ Masacre de Santo Domingo, Gráfico n ${ }^{\circ}$ 6 } \\
\hline $\begin{array}{l}\text { Fecha de Sentencia } \\
\text { de Fondo }\end{array}$ & 30 de noviembre de 2012 \\
\hline Órdenes & $\begin{array}{l}\text { 1. Acto público y reconocimiento de responsabilidad a nivel } \\
\text { internacional } \\
\text { 2. Publicación de las partes pertinentes de la Sentencia } \\
\text { 3ratamiento integral en salud a las víctimas }\end{array}$ \\
\hline $\begin{array}{l}\text { Sentencias de } \\
\text { Supervisión de } \\
\text { Cumplimiento }\end{array}$ & Aún no cuenta con Supervisión de Cumplimiento \\
\hline $\begin{array}{l}\text { Última Supervisión } \\
\text { de Cumplimiento }\end{array}$ & Aún no cuenta con Supervisión de Cumplimiento \\
\hline $\begin{array}{l}\text { Cumplimiento } \\
\text { ITotal (CT) } \\
\begin{array}{l}\text { II Parcial (CP) } \\
\text { III No hay } \\
\text { cumplimiento (NC) }\end{array}\end{array}$ & Aún no cuenta con Supervisión de Cumplimiento \\
\hline
\end{tabular}

\begin{tabular}{|c|c|}
\hline Nombre del caso & Operación Génesis, Gráfico n ${ }^{\circ} 7$ \\
\hline $\begin{array}{l}\text { Fecha de Sentencia } \\
\text { de Fondo }\end{array}$ & 20 de noviembre de 2013 \\
\hline Órdenes & $\begin{array}{l}\text { 1. Investigación por parte del Estado de los hechos del caso, } \\
\text { identificación, juicio y sanción de los responsables } \\
\text { 2. Publicación de las partes pertinentes de la Sentencia } \\
\text { 3. Acto público de reconocimiento de responsabilidad } \\
\text { 4. Tratamiento médico adecuado } \\
\text { 5. Restitución por parte del Estado del respectivo uso, goce y posesión } \\
\text { de los territorios } \\
\text { 6. Garantías estatales de vida digna y de seguridad para el retorno a } \\
\text { los territorios restituidos }\end{array}$ \\
\hline $\begin{array}{l}\text { Sentencias de } \\
\text { Supervisión de } \\
\text { Cumplimiento }\end{array}$ & Aún no cuenta con Supervisión de Cumplimiento \\
\hline $\begin{array}{l}\text { Última Supervisión } \\
\text { de Cumplimiento }\end{array}$ & Aún no cuenta con Supervisión de Cumplimiento \\
\hline $\begin{array}{l}\text { Cumplimiento } \\
\text { I Total (CT) } \\
\text { II Parcial (CP) } \\
\text { III No hay } \\
\text { cumplimiento (NC) }\end{array}$ & Aún no cuenta con Supervisión de Cumplimiento \\
\hline
\end{tabular}


Estadístaicas del cumplimiento de las órdenes de la Corte IDH y cumplimiento de las órdenes respecto del desplazamiento forzado
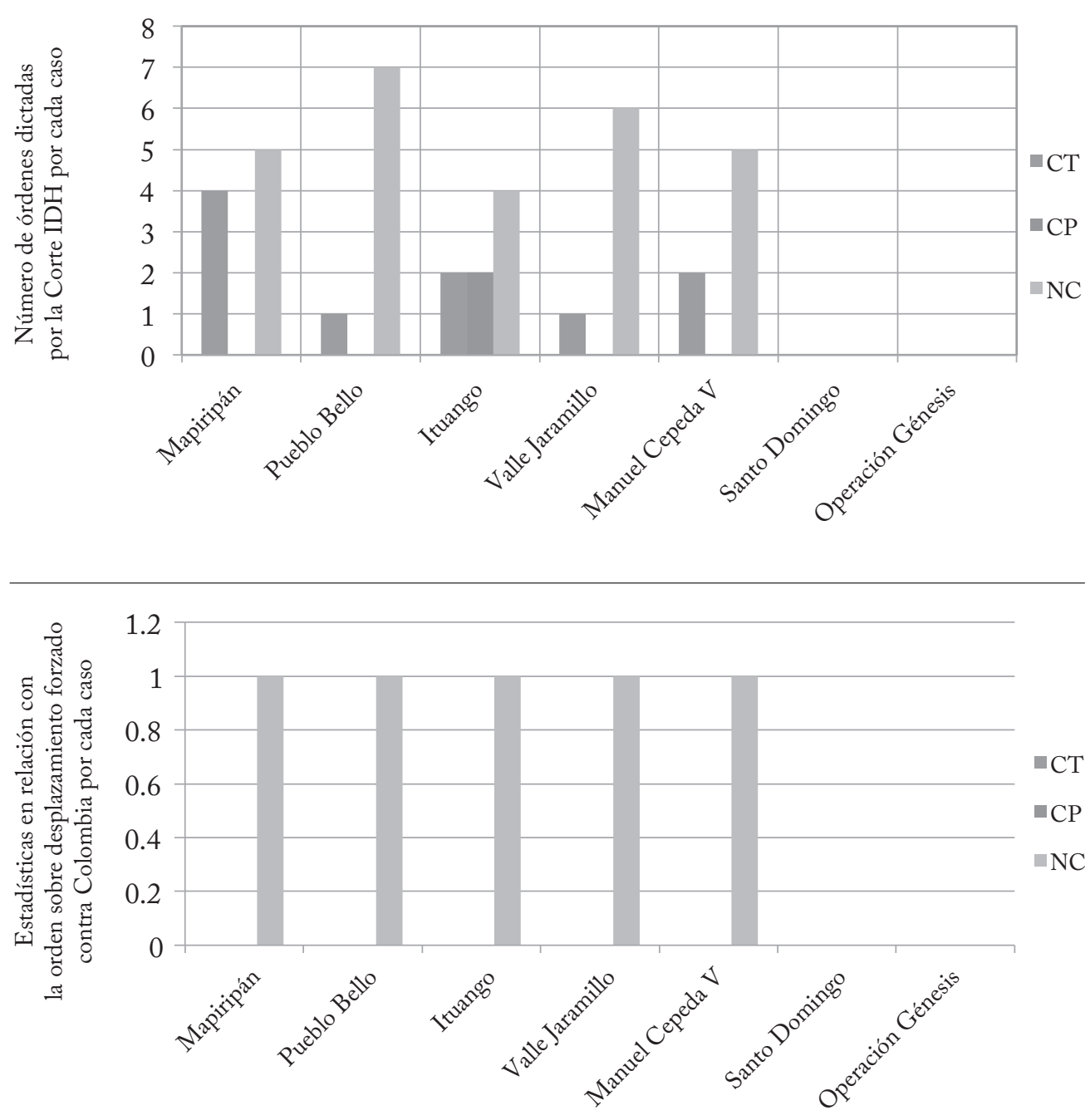

En los anteriores gráficos podemos observar dos situaciones: En un primer momento, los casos llevados ante la Corte IDH contra Colombia en temas relacionados con violación a los derechos humanos y, en segundo lugar, el cumplimiento de las órdenes contra el desplazamiento forzado como consecuencia del conflicto armado.

Frente a esta situación Colombia tiene un promedio de seis a nueve órdenes dictadas por la Corte IDH por cada caso, donde solo una de ellas corresponde a la Garantía de 
Seguridad para las personas víctimas del desplazamiento. Lastimosamente, Colombia respecto de esta orden tiene un incumplimiento total o nulo, lo que implicaría una mayor concentración respecto de este tema en el auge del proceso de paz en el cual se encuentra nuestro país, conjuntamente con el trabajo llevado a cabo con la creación de nuevas entidades que vigilan la protección a las víctimas como uno de los sectores más vulnerados dentro de nuestra sociedad.

\section{Conclusiones finales}

La tardía reglamentación de este fenómeno ha llevado a distintas consecuencias, la falta de cobertura representa un problema grave frente a la vulneración de derechos humanos, y observar que esta situación necesita una solución integral y que sea sostenible en el tiempo.

De las cifras analizadas se evidencia que, además de esta problemática social, también se está complementado por circunstancias que agravan la situación, como la falta de educación de las personas víctimas del desplazamiento o la falta de garantía por parte del Estado y de los gobiernos de turno para implementar políticas que contribuyan a disminuir las cifras alarmantes de desplazamiento interno.

\section{Sobre el análisis estadístico y de seguimiento}

\section{a las sentencias}

Colombia tiene siete condenas ante la Corte IDH por temas relacionados con desplazamiento forzado, todos ellos causados al margen de un conflicto armado interno, de las cuales a ninguna se ha dado un pleno cumplimiento o tan siquiera un cumplimiento parcial. El país, no obstante una continua condena por desplazamiento forzado desde 2005 no ha podido responder a los llamados de la instancia internacional. 
De todas las órdenes dictadas por la Corte IDH contra Colombia, existe un tiempo aproximado de 20 años entre el transcurso de las circunstancias fácticas, la denuncia de los hechos y la sentencia de fondo que ordena el cumplimiento de una Garantía de Seguridad para las personas víctimas del desplazamiento y la Resolución de Supervisión de Cumplimiento, que demuestra cuál ha sido el cumplimiento respecto de estas órdenes.

Según el Centro Nacional de Memoria Histórica en su informe de 2013, el desplazamiento forzado puede presentarse en dos modalidades: una, conocida como desplazamiento forzado selectivo, que aplica a una persona o un grupo determinado de personas víctimas como lo evidenciado en dos de los casos estudiados, a saber: Manuel Cepeda Vargas y Valle Jaramillo, y, otra, un desplazamiento forzado masivo, que aplica para una comunidad determinada lo que se evidencia en las cinco sentencias restantes, como consecuencia del fenómeno conocido como "tierra arrasada". ${ }^{29}$

\section{Sobre los fundamentos jurídicos de las condenas por desplazamiento forzado en el Sistema Interamericano}

El país debe garantizar acceso, retribución y devolución (denominada internamente Restitución, Ley 1448 de 2011) a las personas desplazadas sobre sus propiedades y es a ello a lo que se dirige la Corte IDH con sus puntos resolutivos, prevaleciendo el interés general,y la protección de derechos humanos

29 El fenómeno conocido como "tierra arrasada” es la consecuencia de la incursión de grupos alzados en armas a los distintos municipios, los cuales son obligados a través de la fuerza a abandonar sus tierras y con gran temor entregar sus pertenencias, siendo despojados de sus propios territorios. Recuperado de un informe del Centro Nacional de Memoria Histórica de: http://www.centrodememoriahistorica.gov.co/ en/iniciativas-de-memoria/memorias-desde-la-region?start=10 
sobre situaciones de conflicto armado interno que generan desplazamiento de zonas donde los terrenos son fértiles y facilitan los cultivos, la siembra, la producción de la tierra y que son fuente de ingresos económicos para la gran mayoría de población que vive de la agricultura, pero que por motivos adversos y ajenos a su voluntad deben ser abandonados.

Otra de las conclusiones a las cuales es posible llegar luego de esta investigación es la falta de una norma aplicable a nivel internacional frente al caso de desplazamiento forzado interno, siempre se usa la figura del artículo 22.1 de la Convención Americana de Derechos Humanos ${ }^{30}$ que es el Derecho de Circulación y de Residencia donde se establece que: "Toda persona que se halle legalmente en el territorio de un Estado tiene derecho a circular por el mismo y, a residir en él con sujeción a las disposiciones legales". Esto debido a que Colombia es uno de los pocos países que se ve afectado por la problemática del desplazamiento forzado y que a su vez ratificó esta Convención para hacerla parte del bloque de constitucionalidad del Estado.

Es por ello que el pronunciamiento de la Corte sobre el desplazamiento interno en este país basa su criterio en gran parte en jurisprudencia desarrollada por la Corte Constitucional colombiana, a saber: la Sentencia T-025 de 2004 que establece cierto tipo de órdenes a organismos defensores de derechos humanos en nuestro país, como lo es la Procuraduría General de la Nación, y en conjunto con la Defensoría del Pueblo, para realizar un seguimiento continuo a la implementación de las solicitudes emitidas en dichas sentencias en

30 Convención Americana sobre Derechos Humanos, Art. 22.1 sobre el Derecho a la Circulación y la Residencia. Recuperado de http://www.oas.org/dil/esp/ tratados_b-32_convencion_americana_sobre_derechos_humanos.htm 
pro de la población desplazada como el sector afectado por la violencia.

\section{Referencias bibliográficas}

ACNUR (abril de 2013) IDMc: 28,8 millones de desplazados internos en el mundo en 2012. Recuperado de http://www. acnur.org/t3/noticias/noticia/idmc-288-millones-de-desplazados-internos-en-el-mundo-en-2012-cifra-recordque-incluye-un-aumento-de-cinco-veces-en-siria/.

Alfonso, Ó. A. (2011). La geografía del desplazamiento forzado reciente en Colombia. [Versión de Publicaciones Externado]. Recuperado de http://portal.uexternado.edu.co/pdf/1_ facultadEconomia/Publicaciones/DocumentosDeTrabajo/ documentoDeTrabajoNo332011OscarAAlfonso\%20R..pdf

Carrillo, A. (2009). Internal displacement in Colombia: Humanitarian, economic and social consequences in urban settings and current challenges. International Review of the Red Cross, 91(875), 527-546. Doi: 10.1017/S1816383109990427.

Comisión de Derechos Humanos (1998). Principios Rectores de los Desplazamientos Internos. En Informe del Representante del Secretario General, Sr. Francis M. Deng, con arreglo a la resolución 1997/39 de la Comisión de Derechos Humanos. Recuperado de http://www.acnur.org/t3/filead$\mathrm{min} /$ scripts/doc.php?file=biblioteca/pdf/0022

Convención Americana sobre Derechos Humanos. Artículo 22.1 sobre el Derecho a la Circulación y la Residencia. Recuperado de http://www.oas.org/dil/esp/tratados_b-32_convencion_americana_sobre_derechos_humanos.htm

Corte Interamericana de Derechos Humanos. Página web. Recuperado de http://www.corteidh.or.cr

Corte Interamericana de Derechos Humanos. Sentencia de Fondo la Corte Interamericana de Derechos Humanos Masacre 
de Mapiripán vs. Colombia de 05 de septiembre de 2005. Recuperado de: http://www.corteidh.or.cr/docs/casos/articulos/seriec_134_esp.pdf

Corte Interamericana de Derechos Humanos. Caso de la Masacre de Mapiripán vs. Colombia. Supervisión Cumplimiento de Sentencia. Resolución del Presidente de la Corte Interamericana de Derechos Humanos de 8 de febrero de 2012. Recuperado de http://www.corteidh.or.cr/docs/supervisiones/ mapiripan_23_11_12.pdf

Corte Interamericana de Derechos Humanos. Caso de la Masacre de Mapiripán vs. Colombia. Supervisión de Cumplimiento de Sentencia. Resolución de la Corte Interamericana de Derechos Humanos de 08 de julio de 2009. Recuperado de http://www.corteidh.or.cr/docs/supervisiones/mapiripan_08_07_09.pdf

Corte Interamericana de Derechos Humanos. Caso de la Masacre de Mapiripán vs. Colombia. Supervisión de Cumplimiento de Sentencia. Resolución de la Presidenta de Corte Interamericana de Derechos Humanos de 26 de noviembre de 2008. Recuperado de http://www.corteidh.or.cr/docs/ supervisiones/mapiripan_26_11_08.pdf

Corte Interamericana de Derechos Humanos. Sentencia de Fondo la Corte Interamericana de Derechos Humanos en relación a la Masacre de Pueblo Bello vs. Colombia de 31 de enero de 2006. Recuperado de: http://www.corteidh.or.cr/ docs/casos/articulos/seriec_140_esp.pdf

Corte Interamericana de Derechos Humanos. Caso de la Masacre de Pueblo Bello vs. Colombia. Supervisión Cumplimiento de Sentencia. Resolución del Presidente de la Corte Interamericana de Derechos Humanos de 8 de febrero de 2012. Recuperado de http://www.corteidh.or.cr/docs/supervisiones/bello_08_02_12.pdf 
Corte Interamericana de Derechos Humanos. Caso de la Masacre de Pueblo Bello vs. Colombia. Supervisión de Cumplimiento de Sentencia. Resolución de la Presidenta de Corte Interamericana de Derechos Humanos de 26 de noviembre de 2008. Recuperado de http://www.corteidh.or.cr/docs/ supervisiones/bello_26_11_08.pdf

Corte Interamericana de Derechos Humanos. Sentencia de Fondo la Corte Interamericana de derechos humanos caso de las Masacres de Ituango vs. Colombia de 1 de julio de 2006 recuperado de: http://www.corteidh.or.cr/docs/casos/ articulos/seriec_148_esp.pdf

Corte Interamericana de Derechos Humanos. Caso de las Masacres de Ituango vs. Colombia. Supervisión de Cumplimiento de Sentencia. Resolución de la Corte Interamericana de Derechos Humanos de 21 de mayo de 2013. Recuperado de http://www.corteidh.or.cr/docs/supervisiones/masacres_21_05_13.pdf

Corte Interamericana de Derechos Humanos. Caso de las Masacres de Ituango vs. Colombia. Supervisión de Cumplimiento de Sentencia. Resolución del Presidente de la Corte Interamericana de Derechos Humanos de 8 de febrero de 2012. Recuperado de http://www.corteidh.or.cr/docs/supervisiones/ituango_08_02_12.pdf

Corte Interamericana de Derechos Humanos. Caso de las Masacres de Ituango vs. Colombia. Supervisión de Cumplimiento de Sentencia. Resolución de la Corte Interamericana de Derechos Humanos 28 de febrero de 2011. Recuperado de http://www.corteidh.or.cr/docs/supervisiones/ituango_28_02_11.pdf

Corte Interamericana de Derechos Humanos. Caso de las Masacres de Ituango vs. Colombia. Supervisión de Cumplimiento de Sentencia. Resolución del Presidente de la Corte 
Interamericana de Derechos Humanos de 22 de diciembre de 2010. Recuperado de http:/www.corteidh.or.cr/docs/ supervisiones/ituango_22_12_10.pdf

Corte Interamericana de Derechos Humanos. Caso de las Masacres de Ituango vs. Colombia. Supervisión de Cumplimiento de Sentencia. Resolución de la Corte Interamericana de Derechos Humanos de 07 de julio de 2009. Recuperado de: http://www.corteidh.or.cr/docs/supervisiones/ituango_07_07_09.pdf

Corte Interamericana de Derechos Humanos. Sentencia de Fondo caso Valle Jaramillo y otros vs. Colombia, Sentencia de 27 de noviembre de 2008. Recuperado de http://www.corteidh. or.cr/docs/casos/articulos/seriec_192_esp.pdf

Corte Interamericana de Derechos Humanos. Caso Valle Jaramillo y otros vs. Colombia. Supervisión de Cumplimiento de Sentencia. Resolución del Presidente de la Corte Interamericana de Derechos Humanos de 8 de febrero de 2012. Recuperado de http://www.corteidh.or.cr/docs/supervisiones/jaramillo_08_02_12.pdf

Corte Interamericana de Derechos Humanos. Caso Valle Jaramillo y otros vs. Colombia. Supervisión de Cumplimiento de Sentencia. Resolución de la Corte Interamericana de Derechos Humanos de 15 de mayo de 2011. Recuperado de http://www.corteidh.or.cr/docs/supervisiones/jarami1lo_15_05_11.pdf

Corte Interamericana de Derechos Humanos. Caso Valle Jaramillo y otros vs. Colombia. Supervisión de Cumplimiento de Sentencia. Resolución de la Corte Interamericana de Derechos Humanos de 28 de febrero de 2011. Recuperado de http://www.corteidh.or.cr/docs/supervisiones/jarami1lo_28_02_11.pdf 
Corte Interamericana de Derechos Humanos. Caso Valle Jaramillo y otros vs. Colombia. Supervisión de Cumplimiento de Sentencia. Resolución del Presidente de la Corte Interamericana de Derechos Humanos 21 de diciembre de 2010. Recuperado de http://www.corteidh.or.cr/docs/supervisiones/jaramillo_21_12_10.pdf

Corte Interamericana de Derechos Humanos. Sentencia de Fondo, caso Manuel Cepeda Vargas vs. Colombia, Sentencia de 26 de mayo de 2010. Recuperado de http://www.corteidh. or.cr/docs/casos/articulos/seriec_213_esp.pdf

Corte Interamericana de Derechos Humanos. Caso Manuel Cepeda Vargas vs. Colombia. Supervisión de Cumplimiento de Sentencia. Resolución del Presidente de la Corte Interamericana de Derechos Humanos de 8 de febrero de 2012. Recuperado de http://www.corteidh.or.cr/docs/supervisiones/cepeda_08_02_12.pdf

Corte Interamericana de Derechos Humanos. Caso Manuel Cepeda Vargas vs. Colombia. Supervisión de Cumplimiento de Sentencia. Resolución de la Corte Interamericana de Derechos Humanos de 30 de noviembre de 2011. Recuperado de http://www.corteidh.or.cr/docs/supervisiones/ cepeda_30_11_11.pdf

Corte Interamericana de Derechos Humanos. Sentencia de Fondo, caso Masacre de Santo Domingo vs. Colombia, Sentencia de 30 de noviembre de 2012. Recuperado de http:// www.corteidh.or.cr/docs/casos/articulos/seriec_259_esp.pdf Corte Interamericana de Derechos Humanos. Sentencia de Fondo, caso "Operación Génesis" vs Colombia de 20 de noviembre de 2013, recuperado de http://www.corteidh. or.cr/docs/casos/articulos/seriec_270_esp.pdf

IDMc. Convención Americana sobre Derechos Humanos suscrita en la Conferencia Especializada Interamericana sobre 
Derechos Humanos. Recuperado de http://www.internaldisplacement.org. 2013. http://www.internal-displacement. org/americas/colombia/.

Internal Displacement Monitoring Center IDMC (2013). Recuperado de http://www.internal-displacement.org Pérez, B. (2014). El tema del desplazamiento interno en la agenda pública: Una comparación de su situación en México y Colombia. Cotidiano-Revista de la Realidad Mexicana, 28(183), 7-16.

Piñeros, A. (2012). El desplazamiento forzado en Colombia y la intervención del Estado. Revista de Economía Institucional, 13(26), 169-202.

Rojas Rodríguez, J. E. (1999). Un país que huye, vol. 1. [Versión de Biblioteca codHes]. Recuperado de http://www. codhes.org/index.php/2013-10-01-04-17-32/book/10unpaisquehuye1/8-codhes-bilioteca-comision-seguimiento. 